\title{
THE ROLE OF THE AWN IN THE MOVEMENT OF SEED OF THE WILD OAT
}

M.V.S. RAJU and W. CHAPCO, Biology Department, University of Regina, Regina, SK. S4S OA2

The loose inflorescence (flowering shoot) of the wild oat (Avena fatua L.), an introduced annual weed, bears a large number of spikelets (Fig. 1A). In each spikelet, 2-3 florets (flowers) or occasionally more are developed, each bearing an awn. The awn is elongated and straight in a young floret (Fig. 1A). In a mature seed-bearing floret, on the other hand, the awn is changed into an angular or bent form (Fig. 1B). The awn has two parts to it, a basal thicker and shorter part called the awn and a terminal thinner and longer part, the awl (Fig. 1C). ${ }^{4}$ The bent awn responds to moisture in the environment and changes to a straight condition. In the advent of dry conditions, it can revert to its bent form (Fig. 1C). This change of form is brought about by the mechanical twisting and untwisting of the basal part of the awn. In other words, if this part remains untwisted, the awn would remain straight, and if it is twisted then the entire awn would become bent; the latter type is obtained after water loss (Fig. 1C). ${ }^{4}$ The awl, which does not twist nor untwist, on the other hand, remains straight in both wet and dry conditions. However, it can act as a lever during the twisting and untwisting of the basal part of the awn, thus helping in the crawling or rolling movement of the seed. $^{2,3,5}$

Since the time of Darwin's ${ }^{1}$ report on twisting and untwisting of the awn in response to moisture and grass seed movement there prevails a frequently implied view that the functionally active awn serves to drill the grass seed into an unbroken soil surface.

Unfortunately, there is no experimental evidence to support this view. Some observations and experimental results indicate that the surface movement (two-dimensional) of the active awn propels the seed into cracks or crevices in the soil surface. ${ }^{2,3}$ In addition, as experimentally demonstrated, a more important function of the hygroscopically active (capable of movement in response to available moisture) awn is to dislodge the seed from the parent plant. $^{5,6,7}$

The untwisting (leading to the straight condition) and twisting (leading to the bent condition) of the awn and the awl acting as a lever would make the seed crawl or roll on the ground. Such a movement results in a net displacement from the point where it started; also, a particular pattern of movement is revealed (Fig. 1D). Experiments were conducted to determine the pattern of movement during one cycle of untwisting and twisting of the awn, and to determine the total distance travelled by the seed and the actual distance accomplished. In addition, the importance of the length of the awl with respect to the pattern of seed 

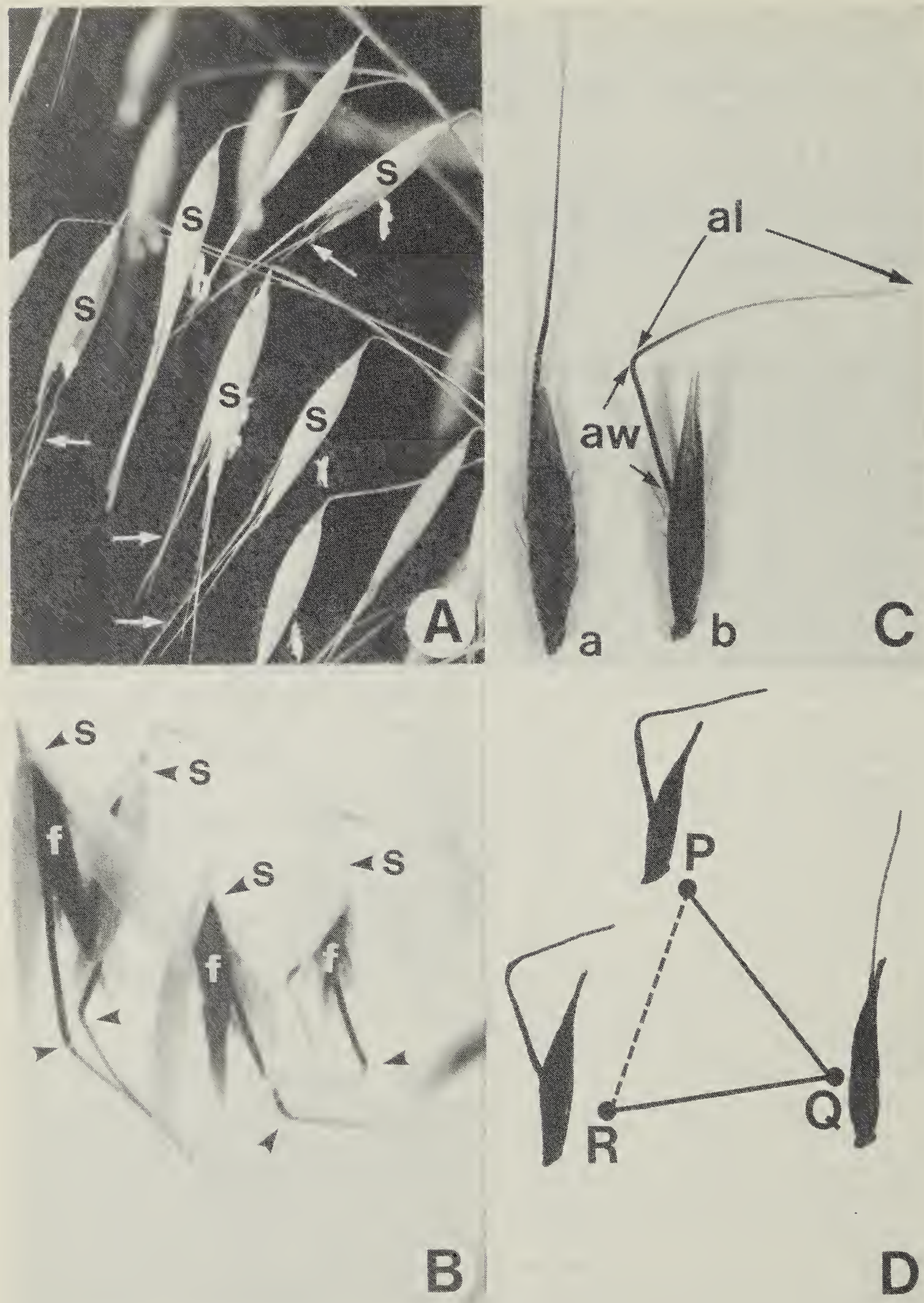

Figure 1: Spikelets, young and old, and seeds of Avena fatua $L$.

A) Young spikelets (s) in an inflorescence. Arrows indicate straight (young) awns, $x 1$.

B) Older spikelets (s) with attached florets(f). Arrowheads point at the bent awns, $x 1$.

C) Water-imbibed seed with its straight awn(a) and the dry seed(b) with its bent awn(aw)and awl(al),x1.

D) Diagram showing the form of the seed and the pattern of seed movement. $P$ to $Q$ is travelled distance of seed caused by the untwisting of awn. $Q$ to $R$ is the travelled distance of seed caused by the twisting (drying) of awn. $P$ to $R$ (interrupted line) is the actual distance accomplished in one cycle from the point of origin $P$. 


\begin{tabular}{|c|c|c|c|}
\hline $\begin{array}{l}\text { Awl (distal part of } \\
\text { awn) length }\end{array}$ & $\begin{array}{l}\text { Awn (proximal part) } \\
\text { length }\end{array}$ & $\begin{array}{c}\text { Total distance } \\
\text { travelled ( } P \text { to } Q \text { to } R \\
\text { in Figure } 1 D \\
\end{array}$ & $\begin{array}{c}\text { Distance } \\
\text { accomplished (from } \\
\mathrm{P} \text { to } \mathrm{R} \text { in Figure } 1 \mathrm{D}\end{array}$ \\
\hline $5 \mathrm{~mm}$ & $9.33 \pm 0.83$ & $24.15 \pm 9.45$ & $15.13 \pm 5.97$ \\
\hline $18 \mathrm{~mm}$ (range: $12-24$ ) & $9.43 \pm 1.01$ & $91.83 \pm 23.54$ & $46.78 \pm 25.41$ \\
\hline Difference & - & $57.68 \pm 4.01(p<0.01)$ & $31.65 \pm 4.13(p<0.01)$ \\
\hline
\end{tabular}

Mean measurements with their standard deviations are given. Sample included 40 seeds in each treatment.

movement and the distance accomplished by the seed, was investigated.

Large mature seeds (more accurately called caryopses in grasses, including the wild oats) of the wild oat (AN 51, a genetic line maintained at the Agriculture Canada Research Station, Regina) were used in the experiments. As shown in fig. 1B, each seed contained well-developed bent awns. For purposes of convenience, a rough wooden board was selected and each seed was placed on it in such a way that the awn with its awl was touching the surface of the board. This point was considered the starting point (Fig. 1A). Then a drop (or two) of water was placed on the awn and the seed. Ordinarily, the twisted (proximal) part of the awn begins to untwist making the awl also turn. The awn can also make six untwist-turns, making the awl also turn six times. ${ }^{4}$ At the end of every turn, the awl, acting as a lever, hits the surface of the board. As it produces considerable amount of torque, the seed turns or rolls in the opposite direction. ${ }^{5}$ As a result of this untwisting of the awn, eventually the entire awn becomes straight, changing from the bent condition (Fig. 1A,D). The straight condition of the awn is a good indication that the awn has imbibed water. As a result of this change of form from the bent to straight form, the seed will have travelled from position $P$ to $Q$ in fig. 1D.
If the seed, with its straight awn, is left alone for some time the awn loses water and twists, eventually assuming the geniculate form (Fig. $1 B, C, D)$. During this change the seed again will have travelled from $Q$ to $R$ (Fig. 1D). Thus in one cycle of this untwisting-twisting, the seed has travelled from position $P$ to $Q$ and then to $R$ (Fig. 1D). This would represent the total distance travelled by the seed. The distance between $P$ and $R$ in fig. 1D was measured, and this distance from the starting point was considered the actual distance accomplished by the seed.

To determine the role of the awl in seed movement, another experiment was set up. The bent awns of mature seeds were treated in such a way that the awl length in each seed was cut to $5 \mathrm{~mm}$. In the control seeds, the awl had an average length of $18 \mathrm{~mm}$. The seed was allowed to have one cycle of untwisting and twisting. Table 1 shows the total mean distance travelled in one cycle of untwisting and twisting, $P$ to $Q$ and to $R$, and the distance accomplished, $P$ to $R$, by the seed (Fig. 1D). The pattern of rolling movement of seeds on the wooden board was very similar both in the treated and the controls (Fig. 1D). However, the distance travelled, $P$ to $Q$ and to $R$, and the distance accomplished (distance between $P$ and $R$ ) by the seed were significantly different (Fig. 1D; Table 1). In other words, the distance travelled and the 
distance accomplished were less for the treated seeds ( $5 \mathrm{~mm}$ long awl) than for those of the controls where the average awl length was $18 \mathrm{~mm}$. Similarly, the distance accomplished by seeds with a shorter awl $(5 \mathrm{~mm})$ was significantly less than that of the seeds with longer awls (Table 1). This difference seems to be important with respect to habitat exploration by the seeds since seeds with longer awls can explore a greater area. Similarly, the accomplished distance is always much smaller than the travelled distance of seeds with either normal or shortened awls. It seems, therefore, that seeds tend to remain very close to the parent plant which, to begin with, has successfully explored and established in the same habitat. This could be one of the reasons that the grasses, including the annual wild oat, with functional awns (capable of movement) have survived in extreme ecological conditions, such as prairies where grasses are a dominant component of the vegetation. The success, following the above scenario, may be accentuated if the following seeds slip into nearby cracks or crevices, if any, in the soil where more favourable conditions may exist for seed germination and survival.

The movement of the wild oat seeds described above may be quite interesting for elementary and high school students to pursue as school science projects. Seeds are common in the agricultural areas of Saskatchewan. Students can collect wild oat seeds and conduct experiments on the movement of the seeds. The role of the length of the awl in seed movement and also the patterns of movement are excellent topics for study.

\section{References}

1. DARWIN, F. 1876. On the hygroscopic mechanism by which certain seeds are enabled to bury themselves in the ground. Trans. Linn. Soc. Lond. Bot. 1:149-167.

2. PEART, M.H. 1979. Experiments on the biological significance of the morphology of seed-dispersal units in grasses. Jour. Ecol. 67:843-863.

3. - 1984. The effects of morphology, orientation and position of grass diaspores on seedling survival. Jour. Ecol. 72:437-453.

4. RAJU, M.V.S. 1984. Studies on the inflorescence of wild oats (Avena fatua). Morphology and anatomy of the awn in relation to its movement. Can. Jour. Bot. 62:2237-2247.

5. RAJU, M.V.S. and R.J. BARTON. 1984. On dislodging caryopsis of wild oats. Bot. Mag. Tolyo 97:127-130.

6. RAJU, M.V.S. and S.N. RAMASWANY. 1983. Studies on the inflorescence of wild oats (Averia fatua). Can. Jour. Bot. 61:74-78.

7. YEUNG, E.C., C.C. CHIMMAPPA and F.S.C. CHEN. 1987. Seed detachment in Avena fatua $L$. Weed Research 27:391-396.

In a radically different setting, the deep unlighted zone of caves around the world, blind white springtails, mites, and beetles feed on fungi and bacteria growing on rotting vegetable matter washed down through ground water. They are eaten in turn by blind white beetles and spiders also specialized for life in perpetual darkness. E.O. Wilson, 1992. The diversity of life. W.W. Norton and Company, New York. 424 pp. 